\title{
Meningkatkan Pemahaman Sifat Magnet Dan Kegunaannya Melalui Model Pembelajaran Demonstrasi Pada Siswa Kelas V SDN I Mambalan Gunungsari Lombok Barat Tahun Pelajaran 2019/2020
}

\author{
Maria putu eka sukahati \\ SDN 1 Mambalan Lombok Barat
}

\begin{abstract}
Abstrak. Model pembelajaran dan alat peraga adalah alat bantu pengajaran yang secara sengaja dan terencana disiapkan atau disediakan guru untuk mempresentasikan dan atau menjelaskan bahan pelajaran serta digunakan siswa untuk dapat terlibat langsung dengan pelajaran Ilmu Pengetahuan Alam ( IPA ). Jenis penelitian ini adalah penelitian kualitatif dengan rancangan penelitian tindakan kelas, yang menggunakan pengembangan motivasi dan keterlibatan siswa. Penelitian ini berangkat dari masalah yang didapat di lapangan, kemudian dianalisis dan direfleksikan. Berdasarkan teori yang menunjang, kemudian dilaksanakan tindakan di lapangan. Penelitian tindakan kelas ini dilaksanakan dua siklus kegiatan yaitu siklus 1 dan siklus 2. Masing-masing siklus terdiri dari dua pertemuan. Masing-masing siklus terdiri dari empat tahap kegiatan yaitu penyusunan rencana tindakan, melaksanakan tindakan, melaksanakan observasi, membuat analisis dilanjutkan dengan refleksi. Pada penelitian ini yang melaksanakan perbaikan pembelajaran adalah guru kelas V SD Negeri I MAMBALAN dibantu oleh teman sejawat yang bertugas mengamati dan mengumpulkan data selama kegiatan pembelajaran berlangsung. Sedangkan sebagai subyek penelitian adalah siswa-siswi kelas V SD Negeri I MAMBALAN tahun pelajaran 2019 / 2020 yang jumlahnya 17 siswa. Hasil penelitian tindakan kelas ini dapat disimpulkan bahwa pembelajaran dengan menggunakan model pembelajaran Demonstration dapat meningkatkan keterlibatan dan pemahaman siswa dalam memahmi materi pelajaran IPA khususnya tentang magnet dankegunaannya. Sebagai bukti keberhasilan dalam pelaksanaan penelitian ini adalah adanya peningkatan kemampuan siswa berdasar hasil evaluasi dan pengamatan yang dilakukan setiap akhir siklus yaitu rata-rata nilai 60,20 sebelum tindakan menjadi 68,8 setelah tindakan siklus I, 80,15 setelah dilaksanakan tindakan siklus II.
\end{abstract}

Kata Kunci : Magnet, Demonstrasi, Pembelajaran

\section{PENDAHULUAN}

Salah satu hambatan yang dialami guru dalam pembelajaran IPA adalah rendahnya tingkat pemahaman siswa terhadap materi ajar, dalam materi mengidentifikasi sifat magnet dan kegunaanya, khususnya materi pengelompokan benda-benda yang bersifat magnetik dan non magnetik. Tugas guru dalam melaksanakan kegiatan pembelajaran bukanlah hanya menyampaikan konsep-konsep materi agar bisa dihafal siswa, tetapi juga perlu memberi pemahaman kepada siswa agar mampu mengimplementasikan dalam kehidupan seharihari. Peningkatan kemampuan siswa dalam suatu proses pembelajaran dapat diketahui melalui kegiatan evaluasi yang dilakukan oleh guru, baik yang mengukur aspek kognitif, afektif maupun aspek psikomotor. Dalam perkembanganya pendidikan memiliki peran yang bersifat universal. Isnaini (2018) Pendidikan memainkan peranan penting dalam hidup dan kehidupan bermasyarakat. Isnaini (2012) Perkembangan dunia pendidikan tinggi mempunyai dampak terhadap proses pendidikan.

Dari hasil evaluasi kegiatan pembelajaran IPA pada siswa kelas V SD Negeri I Mambalan Kecamatan Gunungsari Kabupaten Lobar, dengan Kompetensi Dasar : Mengetahui pengaruh gaya terhadap bentuk dan gerak suatu benda Indikator : mengelompokkan bendabenda yang bersifat magnetis dan non magnetis, yang dilaksanakan pada hari Rabu tanggal, 16 
September 2019, dapat diketahui tingkat penguasaan siswa terhahap materi pelajaran pada analisis hasil tes pembelajaran awal selengkapnya dapat dilihat pada tabel I di halaman berikutnya.

\section{Tabel I. Analisis Hasil Tes Awal}

\begin{tabular}{|c|c|c|c|c|c|c|c|c|c|c|c|c|c|}
\hline \multirow{2}{*}{ No } & \multirow{2}{*}{ Nama Siswa } & \multicolumn{10}{|c|}{ Nomor Soal } & \multirow{2}{*}{$\begin{array}{c}\text { Jml } \\
\text { Benar }\end{array}$} & \multirow{2}{*}{$\begin{array}{c}\text { Keberhasilan } \\
\%\end{array}$} \\
\hline & & 1 & 2 & 3 & 4 & 5 & 6 & 7 & 8 & 9 & 10 & & \\
\hline 1 & Suhailah & 1 & 1 & 0 & 1 & 1 & 0 & 1 & 1 & 0 & 1 & 7 & 70 \\
\hline 2 & Abul A'la Alwarid & 0 & 1 & 1 & 0 & 0 & 1 & 1 & 0 & 1 & 0 & 5 & 50 \\
\hline 3 & Hajar Mu'alif & 1 & 0 & 0 & 1 & 1 & 1 & 1 & 1 & 1 & 1 & 8 & 80 \\
\hline 4 & M. Azar Pamungkas & 0 & 1 & 1 & 0 & 1 & 0 & 1 & 0 & 0 & 1 & 5 & 50 \\
\hline 5 & M. Prayoga & 1 & 1 & 0 & 0 & 0 & 1 & 1 & 0 & 0 & 1 & 5 & 50 \\
\hline 6 & Ah. Ainul Khakim & 0 & 1 & 0 & 1 & 0 & 0 & 0 & 1 & 0 & 1 & 4 & 40 \\
\hline 7 & Nida' Aulady R. & 0 & 0 & 1 & 0 & 0 & 1 & 0 & 0 & 1 & 0 & 3 & 30 \\
\hline 8 & Fatkhur Rozi & 1 & 1 & 0 & 1 & 1 & 0 & 0 & 1 & 1 & 1 & 7 & 70 \\
\hline 9 & Arifatul Hamidah & 0 & 1 & 0 & 1 & 1 & 0 & 1 & 0 & 1 & 0 & 5 & 50 \\
\hline 10 & Irman Purnama & 0 & 1 & 1 & 1 & 1 & 1 & 0 & 1 & 1 & 1 & 8 & 80 \\
\hline 11 & Irwan Kurniawan & 1 & 0 & 1 & 1 & 0 & 1 & 1 & 1 & 1 & 0 & 7 & 70 \\
\hline 12 & Erma Suryani & 0 & 0 & 1 & 0 & 0 & 0 & 1 & 0 & 1 & 0 & 3 & 30 \\
\hline 13 & M. Farikh & 1 & 1 & 0 & 1 & 1 & 0 & 0 & 1 & 1 & 1 & 7 & 70 \\
\hline 14 & Suciati & 0 & 1 & 0 & 1 & 1 & 0 & 1 & 0 & 1 & 0 & 5 & 50 \\
\hline 15 & Abil Arfiansyah & 0 & 1 & 1 & 1 & 1 & 1 & 0 & 1 & 1 & 1 & 8 & 80 \\
\hline 16 & Lailatul Fitriyah & 1 & 0 & 1 & 1 & 0 & 1 & 1 & 1 & 1 & 0 & 7 & 70 \\
\hline 17 & Nofita Puspitasari & 1 & 0 & 1 & 0 & 0 & 0 & 1 & 0 & 1 & 0 & 4 & 40 \\
\hline & Jumlah Salah & 9 & 7 & 7 & 6 & 8 & 9 & 6 & 8 & 4 & 8 & & \\
\hline & Rata-rata & & & & & & &, 83 & & & & & 41,66 \\
\hline
\end{tabular}

Berdasarkan hasil evaluasi tersebut menunjukkan bahwa tingkat penguasaan siswa terhadap materi pelajaran masih relatif rendah karena jumlah siswa yang menguasai materi hanya $41,66 \%$.

Untuk meningkatkan penguasaan dan pemahaman siswa terhadap materi pelajaran IPA, dan memperbaiki kegiatan pembelajaran pada kelas V SDN. I Mambalan Kecamatan Gunungsari Kabupaten Lobar, khususnya Kompetensi Dasar Mengetahui pengaruh gaya terhadap bentuk dan gerak suatu benda, maka dipandang perlu diadakan Penelitian Tindakan Kelas (PTK).

Berdasarkan masalah di atas maka fokus dari perbaikan pembelajaran dalam penelitian ini adalah " Meningkatkan Pemahaman Siswa tentang Sifat Magnet dan Kegunaannya melalui Model Pembelajaran Demonstration pada Siswa kelas V SDN. I Mambalan Kecamatan Gunungsari Kabupaten Lobar

\section{METODE PENELITIAN}

Untuk mengatasi masalah yang telah terumuskan pada pembelajaran IPA kelas V semester II, Standar Kompetensi Menyelidiki pengaruh gaya terhadap bentuk dan gerak suatu benda. Kegiatan perbaikan dilaksanakan dalam 2 siklus kegiatan perbaikan pembelajaran dengan waktu 35 menit untuk tiap siklus.

\section{a. Rencana Perbaikan Pembelajaran Siklus 1}

Rencana perbaikan pembelajaran siklus 1 dengan Kompetensi Dasar Menyelidiki gaya terhadap bentuk gerak suatu benda, dengan Indikator Siswa dapat menyebutkan sifat-sifat magnet dan kegunaannya.

Tujuan pembelajaran yang ingin dicapai adalah :

- Siswa dapat menyebutkan macam-macam magnet dengan benar

- Siswa dapat menyebutkan sifat benda-benda magnetis dan non magnetis.

Tujuan perbaikan yang ingin dicapai adalah :

- Siswa dapat menyebutkan bentuk magnet buatan dengan benar

- Siswa dapat menyebutkan dua macam benda magnetik dengan benar

- Siswa dapat menyebutkan dua macam benda non magnetik dengan benar

- Siswa dapat menyebutkan dua kegunaan magnet dengan benar.

b.Rencana Perbaikan Pembelajaran Siklus II

Dari hasil observasi, diskusi dengan teman sejawat serta refleksi setelah pelaksanaan perbaikan pembelajaran I, maka disusun rencana perbaikan pembelajaran siklus II, dengan Kompetensi Dasar Menyelidiki gaya terhadap bentuk dan gerak satu benda, hasil belajar yang ingin dicapai adalah siswa dapat mengidentifikasi sifat magnet dan kegunaannya, sedang tujuan perbaikan pembelajaran yang ingin dicapai adalah siswa dapat dengan mudah menyebutkan sifat-sifat magnet dan kegunaannya menggunakan metode eksperimen, Sumber bahan, Kurikulum, buku IPA kelas V, Lembar Kerja Siswa (LKS) buatan guru.

Metode yang digunakan dalam perbaikan pembelajaran siklus II ini adalah metode demonstrasi, tanya jawab dan pemberian tugas. Langkah-langkah dalam perbaikan pembelajaran siklus II meliputi : kegiatan awal (apersepsi) 5 menit, dilanjutkan kegiatan inti 
selama 25 menit, kemudian guru memberi Kegiatan akhir 5 menit guru menyimpulkan dan memberi penguatan, siswa diberi PR sebagai tindak lanjut. Evaluasi dilaksanakan menggunakan tes tulis. Pembeda antara rencana perbaikan pembelajaran siklus I dan rencana perbaikan pembelajaran II terletak pada komposisi kegiatan inti.

Komposisi kegiatan inti pada rencana perbaikan pembelajaran siklus I yaitu $\geq 70 \%$ untuk peningkatan pemahaman siswa tentang sifat magnet dan kegunaannya dan $\geq 30 \%$ melakukan eksperimen. Pada rencana pembelajaran II komposisi kegiatan inti adalah $\leq$ $80 \%$ untuk peningkatan pemahaman siswa tentang sifat magnet dan kegunaannya dan $>20$ $\%$ untuk melakukan eksperimen tes dalam proses dan tes akhir digunakan untuk mengetahui tingkat penguasaan siswa tentang sifat magnet dan kegunaannya.

\section{Pelaksanaan Perbaikan}

a. Pelaksanaan Perbaikan Pembelajaran Siklus I

\section{1) Prosedur Umum}

Sesuai dengan rencana yang telah dibuat, pelaksanaan perbaikan pembelajaran siklus 1 dilaksanakan pada tanggal, 2 September 2019, dalam pelaksanaan kegiatan perbaikan pembelajaran dibantu oleh ibu Denda Suharniwati, S.Pd selaku teman sejawat yang bertugas mengamati dan mengumpulkan data selama kegiatan pembelajaran berlangsung. Adapun tujuan perbaikan pembelajaran adalah Meningkatkan pemahaman siswa tentang sifat magnet dan pemahamannya menggunaan metode eksperimen. Secara garis besar langkahlangkah pembelajaran siklus I adalah sebagai berikut :

- Kegiatan awal ( apersepsi)

- Menyampaikan tujuan pembelajaran

- Guru menyiapkan magnet

- Menjelaskan materi pelajaran

- Memberi tugas pada siswa untuk mengerjakan LKS

- Mendiskusikan hasil kerja siswa

- Memberikan penilaian

Jurnal Pendidikan Mandala
- Menyimpulkan materi pelajaran

- Memberi tugas rumah (PR) sebagai tindak lanjut.

\section{2) Prosedur Khusus}

Sesuai dengan tujuan untuk mengatasi permasalahan yang dihadapi dalam kegiatan pembelajaran IPA yaitu pemahaman siswa terhadap sifat magnet dan kegunaannya masih rendah, maka kegiatan khusus yang perlu diperhatikan dalam pelaksanaan perbaikan pembelajaran pada siklus I adalah penggunaan metode eksperimen untuk membantu meningkatkan pemahaman siswa tentang sifat magnet dan kegunaannya. Peningkatan penguasaan siswa terhadap materi pada kegiatan perbaikan pembelajaran siklus I adalah $\geq 70 \%$ dan $\geq 30 \%$ melakukan eksperimen.

\section{b. Pelaksanaan Perbaikan Pembelajaran II}

$$
\text { Perbaikan Pembelajaran II }
$$

dilaksanakan pada hari Rabu, tanggal, 9 September 2019, kegiatan perbaikan pembelajaran masih mengacu pada tujuan perbaikan I yaitu membantu siswa dalam meningkatkan pemahaman tentang sifat magnet dan kegunaannya.

\section{2) Prosedur Khusus}

Dalam pelaksanaan perbaikan pembelajaran siklus II, masih menggunakan metode eksperimen, namun lebih menitik beratkan pada pencapaian indikator yaitu siswa dapat mengelompokkan benda-benda yang bersifat magnetik dan non magnetik. Kegiatan khusus yang menjadi fokus perbaikan pembelajaran siklus II ialah memberi kesempatan kepada semua siswa meningkatkan pemahamnan tentang sifat magnet dan kegunaannya $\leq 80 \%$ dan $>20 \%$ untuk melakukan eksperimen. Dengan metode ekperimen sebagai upaya untuk meningkatkan motivasi belajar siswa, sehingga tujuan pembelajaran akan lebih mudah dicapai.

\section{Pengumpulan Data}

Dalam pelaksanaan perbaikan pembelajaran siklus I dengan metode 
eksperimen, tanya jawab dan meminta kepada siswa melakukan eksperimen, ternyata dapat membantu siswa dalam memahami materi pelajaran. Belum optimalnya pemahaman siswa dalam pembelajaran karena belum semua siswa mendapat kesempatan mencoba melakukan eksperimen karena keterbatasan waktu. Pada pelaksanaan perbaikan pembelajaran siklus II, menggunakan cara memberi kesempatan pada semua siswa untuk mencoba melakukan eksperimen, dengan strategi tersebut ternyata juga dapat meningkatkan pemahaman dan motivasi siswa terhadap materi pelajaran, karena semakin tinggi motivasi belajar siswa, akan meningkat pula hasil belajar siswa.

\section{Refleksi}

Dalam pelaksanaan perbaikan pembelajaran siklus I, salah satu metode yang digunakan adalah metode eksperimen. Dengan memberi tugas kepada siswa untuk melakukan percobaan, tujuannya adalah untuk membantu pemahaman siswa dalam menyelesaikan soal tentang sifat magnet dan kegunaannya dalam pembelajaran IPA dapat tercapai meskipun belum optimal sesuai yang diharapkan.

Melalui diskusi dengan teman sejawat yang melaksanakan pengamatan selama kegiatan perbaikan pembelajaran berlangsung diperoleh masukan bahwa kekurangan dalam kegiatan perbaikan pembelajaran adalah guru masih kurang dalam pemberian kesempatan pada siswa untuk mendemonstrasikan / melakukan eksperimen. Tentang media yang digunakan dalam pembelajaran, teman sejawat yang melaksanakan pengamatan berkomentar, bahwa seharusnya guru menambah jumlah media yang digunakan, agar semua siswa mendapat kesempatan untuk mencoba melakukan percobaan, sehingga dapat merangsang siswa untuk terlibat secara aktif dalam proses pembelajaran, sehingga media tersebut bukan hanya sekedar pemusat perhatian siswa.

Melalui refleksi dan diskusi dengan teman sejawat, untuk memperbaiki kegiatan perbaikan pembelajaran siklus I dengan tujuan membantu pemahaman siswa tentang sifat magnet dan kegunaannya dalam pembelajaran IPA. Beberapa alternatif yang dapat digunakan yaitu :

1) Menambah waktu pelaksanaan menjadi $2 \mathrm{x}$ 35 menit tiap siklus

2) Menambah jumlah media dan pemberian kesempatan pada siswa untuk melakukan percobaan

3) Mengganti model pembelajaran

Hasil refleksi dari pelaksanaan perbaikan pembelajaran siklus I menjadi acuan untuk menyusun rencana perbaikan pembelajaran siklus II. Dari 3 alternatif yang ditawarkan untuk membantu meningkatan pemahaman siswa tentang sifat magnet dan kegunaannya yaitu menambah jumlah media dan memperbanyak pemberian kesempatan siswa agar proses pembelajaran lebih efektif.

\section{HASIL DAN PEMBAHASAN}

\section{A. Hasil Penelitian}

Perbaikan pembelajaran ini dilaksanakan di kelas V SD Negeri I Mambalan Kecamatan Gunungsari Kabupaten Lobar. Perbaikan Pembelajaran terdiri dari 2 siklus. Siklus I dilaksanakan pada hari Rabu tanggal, 2 September 2019, jam 07.00 - 08.20, dan siklus II dilaksanakan pada hari Rabu, tanggal 9 September 2019 jam $07.00-08.20$

\section{Siklus I}

Dari hasil pengamatan selama proses pembelajaran IPA hanya menggunakan pendekatan metode ceramah, Tanya jawab dan pemberia tugas. Data yang diambil adalah :

a. Respon siswa dalam pembelajaran IPA khususnya sifat magnet dan kegunaannya

b. Peranan guru di kelas selama kegiatan berlangsung

c. Tingkat daya serap siswa terhadap materi pelajaran.

Berdasarkan hasil tes formatif tentang magnet dan kegunaannya masih belum berhasil, yang berhasil hanya 2 siswa ( $11 \%$ ) yang berhasil cukup 10 siawa atau ( $60 \%$ ) dan masih belum berhasil adalah 5 siswa ( $29 \%$ ) hasil ratarata 6,2 taraf seraf $6,2 \%$ dari 17 siswa.hal ini membuktikan bahwa pada perbaikan siklus I 
belum mencapai Kreteria Ketuntasan Minimal yaitu 70, sehingga perlu diadakan perbaikan pembelajaran siklus II. Adapun hasil tes akhir pada pembelajaran siklus I selengkapnya adalah sebagai berikut ;

\begin{tabular}{|c|l|c|c|c|}
\hline NO & \multicolumn{1}{|c|}{ NAMA SISWA } & Nilai & $\begin{array}{c}\text { Penguasaan } \\
\text { Materi }\end{array}$ & Ket \\
\hline 1 & Suhailah & 60 & $60 \%$ & \\
\hline 2 & Abul A'la Alwarid & 60 & $60 \%$ & \\
\hline 3 & Hajar Mu'alif & 50 & $50 \%$ & \\
\hline 4 & M. Azar Pamungkas & 70 & $70 \%$ & \\
\hline 5 & M. Prayoga & 60 & $60 \%$ & \\
\hline 6 & Ah. Ainul Khakim & 70 & $70 \%$ & \\
\hline 7 & Nida' Aulady R. & 60 & $60 \%$ & \\
\hline 8 & Fatkhur Rozi & 70 & $70 \%$ & \\
\hline 9 & Arifatul Hamidah & 60 & $60 \%$ & \\
\hline 10 & Irman Purnama & 90 & $90 \%$ & \\
\hline 11 & Irwan Kurniawan & 70 & $70 \%$ & \\
\hline 12 & Erma Suryani & 80 & $80 \%$ & \\
\hline 13 & M. Farikh & 50 & $50 \%$ & \\
\hline 14 & Suciati & 60 & $60 \%$ & \\
\hline 15 & Abil Arfiansyah & 50 & $50 \%$ & \\
\hline 16 & Lailatul Fitriyah & 60 & $60 \%$ & \\
\hline 17 & Nofita Puspitasari & 60 & $60 \%$ & \\
\hline & & 6,20 & 6,20 & \\
\hline
\end{tabular}

\section{Siklus II}

Pada perbaikan pembelajaran siklus II merupakan pemantapan dari perbaikan siklus I, dalam perbaikan pembelajaran siklus II ini menggunakan penerapan metode diskusi, karena pada perbaikan pembelajaran siklus I kurang optimal hanya menggunakan Tanya jawab. Pada siklus II ini siswa akan membuktikan sendiri tentang sifat magnet dan kegunaannya melalui eksperimen. Setelah diadakan tes akhir pada perbaikan pembelajaran II menunjukkan peningkatan yang cukup signifikan karena adanya peningkatan pemahaman siswa tentang konsep sifat magnet dan kegunaannya, hal ini dibuktikan dari nilai hasil tes akhir pada siklus II. Hasil selengkapnya adalah sebagai berikut.

\begin{tabular}{|c|l|c|c|c|}
\hline NO & \multicolumn{1}{|c|}{ NAMA SISWA } & Nilai & $\begin{array}{c}\text { Penguasaan } \\
\text { Materi }\end{array}$ & Ket \\
\hline 1 & Suhailah & 80 & $80 \%$ & \\
\hline 2 & Abul A'la Alwarid & 70 & $70 \%$ & \\
\hline 3 & Hajar Mu'alif & 80 & $80 \%$ & \\
\hline 4 & M. Azar Pamungkas & 80 & $80 \%$ & \\
\hline 5 & M. Prayoga & 80 & $80 \%$ & \\
\hline 6 & Ah. Ainul Khakim & 90 & $90 \%$ & \\
\hline 7 & Nida' Aulady R. & 100 & $100 \%$ & \\
\hline 8 & Fatkhur Rozi & 70 & $70 \%$ & \\
\hline 9 & Arifatul Hamidah & 80 & $80 \%$ & \\
\hline 10 & Irman Purnama & 90 & $90 \%$ & \\
\hline 11 & Irwan Kurniawan & 70 & $70 \%$ & \\
\hline 12 & Erma Suryani & 80 & $80 \%$ & \\
\hline 13 & M. Farikh & 80 & $80 \%$ & \\
\hline 14 & Suciati & 80 & $80 \%$ & \\
\hline 15 & Abil Arfiansyah & 70 & $70 \%$ & \\
\hline 16 & Lailatul Fitriyah & 80 & $80 \%$ & \\
\hline 17 & Nofita Puspitasari & 90 & $90 \%$ & \\
\hline & & 8,15 & 8,15 & \\
\hline
\end{tabular}

\section{Observasi dan Refleksi a. Observasi}

Dari observasi yang dilakukan oleh teman sejawat pada perbaikan pembelajaran siklus I menunjukkan bahwa sebagian besar siswa yang semula tidak memahami tentang sifat magnet dan kegunaannya melalui penjelasan dan tanya jawab dan kegiatan pembelajaran terfokus pada guru sehingga siswa kurang aktif dan hanya menjadi pendengar, sebagian siswa juga tidak mau berpendapat.

Pada pelaksanaan perbaikan pembelajaran siklus I, pemahaman siswa terhadap materi belum optimal tingkat pemahaman siswa terhadap materi pelajaran, karena guru tidak menggunakan alat perga ( berupa magnet) dan hanya menggunakan gambar yang ditampilkan saja, kurang memberi motivasi, monoton dan tidak menyenenangkan.

$$
\text { Pada pelaksanaan perbaikan }
$$
pembelajaran siklus II, yaitu menggunakan metode eksperimen dan tanya jawab, ternyata juga dapat meningkatkan keterlibatan siswa dalam pembelajaran. Semakin tinggi motivasi belajar siswa, akan semakin baik hasil belajar siswa.

Hal ini terbukti dengan adanya peningkatan rata-rata tingkat penguasaan siswa terhadap materi pelajaran dari yang semula hanya sebesar $6,2 \%$ pada pelaksanaan ppembelajaran siklus I dan meningkat lagi menjadi $81,5 \%$ pada pelaksanaan perbaikan pembelajaran siklus II.

\section{b. Refleksi}

Dalam pelaksanaan perbaikan pembelajaran siklus I, salah satu metode yang digunakan adalah metode ceramah dan Tanya jawab. Dengan memberi penjelasan kepada siswa dan memberi pertanyaan pada siswa yang lain untuk melanjutkan menjawab, tujuannya adalah untuk melibatkan siswa secara aktif dalam pembelajaran dapat tercapai meskipun belum optimal.

Melalui diskusi dengan teman sejawat yang melaksanakan pengamatan selama kegiatan perbaikan pembelajaran berlangsung diperoleh masukkan bahwa kekurangan dalam 
kegiatan perbaikan pembelajaran adalah kegiatan pembelajaran ter focus pada guru dan alat peraga yang dipakai dalam pembelajaran kurang efektif.

Mengenai media yang digunakan dalam pembelajaran, teman sejawat yang melaksanakan pengamatan berkomentar, bahwa seharusnya guru menggunakan media yang dapat merangsang siswa untuk terlibat secara aktif dalam proses pembelajaran, bukan hanya sekedar pemusat perhatian siswa.

Melalui refleksi dan diskusi dengan temansejawat, untuk memperbaiki kegiatan perbaikan pembelajaran siklus I dengan tujuan meningkatkan keterlibatan siswa dalam pembelajaran. Beberapa alternatif yang dapat digunakan yaitu :

1) Menambah waktu pelaksanaan menjadi 2 x 35 menit tiap siklus

2) Menggunakan metode dan media pembelajaran yang lebih bervariasi.

3) Mengganti medel pembelajaran

Hasil refleksi dari pelaksanaan perbaikan pembelajaran siklus I menjadi acuan untuk menyusun rencana perbaikan pembelajaran siklus II. Dari 3 alternatif yang ditawarkan untuk melibatkan siswa secara aktif dalam pembelajaran menggunakan metode eksperimen dan media pembelajaran yaitu magnet pembelajaran lebih efektif.

Berdasarkan hasil pengamatan teman sejawat ternyata motode eksperimen yang diterapkan guru tidak hanya dapat melibatkan siswa di dalam pembelajaran secara efektif tetapi sekaligus dapat menjangkau indikator.

Nilai evaluasi hasil perbaikan pembelajaran siklus II menunjukkan rata-rata tingkat penguasaan siswa terhadap materi pelajaran sebesar $81,5 \%$.

\section{PEMBAHASAN}

Dalam pelaksanaan perbaikan pembelajaran siklus I, perbaikan yang terjadi adalah meningkatnya pemahaman siswa terhadap materi pelajaran melalui metode Demonstrasi dan alat peraga berupa magnet.
Namun pemahaman dan keterlibatan siswa dalam pembelajaran belum optimal. Hal ini terjadi karena proses pemebelajaran terfokus dalam dari guru.

Dengan media berupa magnet dimaksudkan semua siswa aktif dalam pembelajaran. Untuk mengatasi siswa yang tidak memperhatikan guru menggunakan cara melontarkan pertanyaan kepada siswa yang tidak memperhatikan, kemudian meminta kepada siswa lain lagi untuk membantu menjawab pertanyaan guru.

Dalam pelaksanaan perbaikan pembelajaran siklus II, Guru menggunakan metode eksperimen dalam proses pembelajaran dan lata peraga magnet karena metode pembelajaran ini dinilai cocok untuk mencapai rumusan Tujuan Perbaikan Pembelajaran.

Dengan metode eksperimen setiap siswa mendapat kesempatan untuk mencoba dan menemukan sendiri sifat-sifat magnet dan kegunaannya, inilah yang dapat melibatkan siswa secara aktif dalam pembelajaran, dan sekaligus dapat meningkatkan pemahaman siswa tentan sifat-sifat magnet.

\section{KESIMPULAN}

Dari hasil pelaksanaan perbaikan pembelajaran, dapat ditarik kesimpulan sebagai Pemilihan dan penggunaan, media secara efektif dapat melibatkan siswa secara aktif dalam pembelajaran, penggunaan metode dan media pembelajaran perlu disesuaikan dengan model pembelajara dan metode eksperimen dapat digunakan untuk melibatkan siswa dalam pembelajaran sehingga guru hendaknya menyesuaikan penggunaan media pembelajaran dengan model pembelajaran dan memperhatikan siswa yang tidak aktif dalam proses pembelajaran.

\section{DAFTAR PUSTAKA}

Dienje Bonnon Rumumpuk,1988.Media Instruksiona IPS, Jakarta,Depdikbud

Dimyati, Mujiono,1994. Belajar dan Pembelajaran, Jakarta,Depdikbud Dimyati,2002.Psikologi

Pendidikan,Jakarta,Rineka Cipta 
Gagne Robert Bringgs j,1978.Principles of Instruksional, New Jersey, Dessign Holt Rinehart \& Viston

Isnaini, LMY. 2012. Pembinaan Olahraga Dalam Pembentukan Karakter. Surabaya. 9786027508 75-0 12 (978 6027508 75-0), 12 vol.

Isnaini, LMY., Hananingsih, W. 2018. Persepsi dan Motivasi Mahasiswa Pada UKM Bola Basket di Universitas Nahdlatul Ulama NTB. JISIP (Jurnal Ilmu Sosial dan Pendidikan) 2 (1).

Isnaini, LMY., Soegiyanto., Sugiharto., Sulaiaman. Effect of Hyperbaric Oxygen and Vital Capacity of Lungs on Maximum Aerobic Capacity and Anaerobic Capacity and Anaerobic Endurance to Basketball Players. International Journal of Pharmaceutical Research. Volume 11, issue 3, JulySept, 2019

Muhibbin Syah,2004.Psikologi Pendidikan Dalam PendekatanBaru,Bandung. PT. Remaja Rosda Karya.

Suryabrata,Sumadi,2003.Metodologi

Penelitian,Jakarta,PT.Raja Graffindo Persada Universitas Terbuka

Wardani, I.G.A.K, Kuswaya Wihardit, Noehi Nasution. (2006) Penelitian Tindakan Kelas. Jakarta : Universitas Terbuka.

Wardani, I.G.A.K, Siti Julaeha, Ngadi Marsinah. (2006) Pemantapan Kemampuan Kemampuan Profesional (Panduan). Jakarta : Universitas Terbuka.

Zainul, Asnawi dan Mulayan, Agus . (2014). Tes dan Asesmen di SD. Jakarta : 